\title{
Juvenility, Flowering, and the Effects of a Limited Inductive Photoperiod in Coreopsis grandiflora and C. lanceolata
}

\author{
M. Peggy Damann ${ }^{1}$ and Robert E. Lyons ${ }^{2}$ \\ Department of Horticulture, Virginia Polytechnic Institute and State University, Blacksburg, \\ VA 24061-0327 \\ Additional index words. Asteraceae, long-day plant, bolting
}

\begin{abstract}
Juvenility and flowering requirements of Coreopsis grandiflora Hogg ex Sweet. 'Sunray' and C. lanceolata L. 'Early Sunrise' were examined by growing plants under short days (SD) and transferring them to long days (LD) upon reaching the designated true leaf stages. Neither cultivar flowered in continuous SD, and 'Sunray' remained vegetative in LD. However, LD induced flowering in 'Early Sunrise' plants in each leaf count treatment and the loss of juvenility was gradual, with most rapid flowering occurring when plants were transferred to LD at the 16 leaf stage. The limited inductive photoperiod (LIP) inhibited stem elongation of 'Early Sunrise' plants in all LD treatments and selectively inhibited axillary flower bud development compared to plants grown in continuous LD. LIP did not affect scape length at first flower even though plant height was significantly diminished if given relatively few LD before transfer to SD. Height reduction was attributed to LIP inhibition of stem elongation with no significant loss of axillary flower bud potential.
\end{abstract}

Plants cultivated within controlled environments for aesthetic value are the mainstay of the commercial floriculture industry. Contrary to an expressed consumer desire for an expanded choice of plant material (Cathey, 1981; Herbert, 1977), <20 ornamental species make up the majority of cultivated floriculture offerings to the public (Anon., 1988).

Coreopsis, or tickseed, is in the Asteraceae and native to the Americas and tropical Africa (Liberty Hyde Bailey Hortorium, 1976). Two of the most popular species are $C$. grandiflora and $C$. lanceolata, which are commonly grown as herbaceous perennials. The cultivar Sunray is usually listed under C. grandiflora (Clausen and Ekstrom, 1989); 'Early Sunrise'. listed under C. lanceolata, is a new introduction that flowers during the summer following a spring sowing. These species have many similarities and their hybrids are frequently confused, perpetuating conflicting reports of growth patterns and flowering mechanisms. Confusion also exists in the literature on botanical nomenclature and photoperiodic classification of Coreopsis species. Coreopsis lanceolata grandiflora was classified as a long day (LD) plant by Laurie and Poesch (1932). whereas Ketellapper and Barbaro (1966) determined $C$. grandiflora, most likely the same species as studied by Laurie and Poesch, to be a short-long day (SLD) plant. However, the LD requirement was judged not to be absolute. Coreopsis grandiflora remains classified as a SLD plant (Metzger, 1988).

A period of juvenility, described as a physiologically based time when a plant is insensitive to conditions that promote floral initiation (Bernier et al., 1981a). is common in plants. For some species the period ofjuvenility is only a few days (Cumming, 1959; Friend, 1968). whereas some woody species remain juvenile for30 to 40 years (Hackett, 1985). Many photoperiodic herbaceous species pass through juvenility gradually, characterized by a period of increased sensitivity to daylength rather than a total inability to flower (Bernier et al., 1981 a). Ketellapper and Barbaro

Received for publication 5 Aug. 1992. Accepted for publication 5 Dec. 1992. The cost of publishing this paper was defrayed in part by the payment of page charges. Under postal regulations, this paper therefore must be hereby marked advertisement solely to indicate this fact.

'Former Graduate Student.

${ }^{2}$ Associate Professor.
(1966) reported that $C$. grandiflora passed through a juvenile phase during which the plants exhibited little or no sensitivity to inductive conditions.

Various theories to quantify the end of juvenility have been proposed. Purvis (1934) postulated that a minimum number of leaves was required before floral initiation could occur. The transition from juvenility to maturity for several plants was proposed to occur when a photosynthetic leaf area sufficient to sustain flowering and fruiting was reached (Schwabe, 1976; Wareing and Frydman, 1976). However, systematic removal of leaves, even to the extreme of leaving only the rosette stem and shoot apex intact, failed to alter the flowering response of Eschscholtzia californica Cham., indicating that a specific node count may affect flora1 induction by LD (Lyons and Booze-Daniels, 1986). This species became more responsive to inductive conditions as it aged (Lyons and Neale, 1983); it flowered most rapidly once transferred to inductive LD if previously grown in noninductive SD to the 10 unfolded true leaf stage (Lyons and Booze-Daniels, 1986). Further, Carter (1986) demonstrated that if the inductive LD stimulus were terminated before eight cycles, flower formation and anthesis did not occur. Gaillardia pulchella Foug. and Rudbeckia hirta L. 'Marmalade' exhibited a similar response to LD with the onset of maturity, being most sensitive to LD if first allowed to form 20 and 19 expanded leaves in short days (SD), respectively (Bourke, 1990).

Rosette plants, including Coreopsis lanceolata and C. grandiflora, usually bolt before flowering. The bolting and flowering process, comprised of stem and scape elongation, has been studied extensively as a single response (Greulach, 1942; Mumeek, 1936, 1940; Orvos and Lyons, 1989), but less as a pair of independent mechanisms. Photoperiodic inhibition was defined by Mumeek (1936) and used to describe the inhibition of bolting height that occurred when Rudbeckia plants were transferred to SD following floral initiation in LD. Subsequent examination of six Asteraceae species revealed that photoperiodic inhibition of stem elongation with simultaneous flowering occurred exclusively in $R$. hirta

Abbreviations: LD, long days: LIP, limited inductive photoperiod; SD, short days; SLD, short-long day. 
(Greulach, 1942). Rudbeckia hirta 'Marmalade' flowered following as few as four LD cycles; however, plants were only one-half the height of those grown in continuous LD (Orvos and Lyons, 1989).

Limited inductive photoperiod (LIP), an expansion of Murneek's (1936) concept of "photoperiodic inhibition," is a method whereby the plant is given the minimum number of inductive cycles to initiate flowering before transfer back to non-inductive conditions. The LIP promotes flowering, but bolting-related stem elongation stops upon transfer of plants back to SD. LIP effectively controlled plant height in E. californica by inhibiting stem elongation without affecting scape length, resulting in plants that were shorter and better proportioned to the container than those that remained in LD until anthesis (Carter, 1986).

Currently, Coreopsis species have minor commercial significance as a greenhouse crop, but are becoming more popular with gardeners because of their cold hardiness, attractive foliage, beautiful flowers, and tolerance of diverse environmental conditions. For Coreopsis to become marketable potted ornamentals, research must elucidate their flowering mechanisms to facilitate control, manipulation, and scheduling of blooming so that flowers are present at the time of sale. Hence, our objectives were to 1) examine the flowering requirements in Coreopsis grandiflora 'Sunray' and Coreopsis lanceolata 'Early Sunrise' by quantifying the end of juvenility, 2) determine the minimum number of LD cycles required for induction and initiation of flowering in 'Early Sunrise', and 3) to examine the effects of LIP on stem and scape elongation in 'Early Sunrise'.

\section{Materials and Methods}

In each experiment, seeds were sown in a medium of 2 parts vermiculite : 1 part peatmoss $(\mathrm{v} / \mathrm{v})$ and placed under intermittent mist. Misting was terminated upon germination, and all seedlings were moved to SD. While still in the cotyledonary stage, plants were transplanted into $500 \mathrm{ml}(10 \mathrm{~cm})$ plastic pots using a mixture of 3 parts peatmoss : 1 part perlite : 1 part vermiculite (by volume). LD conditions were created by night interruption from 2200 to $0200 \mathrm{HR}$ with $60 \mathrm{~W}$ incandescent bulbs strung overhead to provide 3 to $4 \mu \mathrm{mol} \cdot \mathrm{m}^{-2} \cdot \mathrm{s}^{-1}$ photosynthetic photon flux density (PPFD) at plant height. SD conditions were created by covering the plants from 1700 to $0800 \mathrm{HR}$ with $100 \%$ light exclusion black sateen cloth. Germination was at 19 to $21 \mathrm{C}$ day and night; growth thereafter was at 16 to $18 \mathrm{C}$ nights and 26 to $30 \mathrm{C}$ days. After transplanting, plants were fertilized weekly during irrigation with $400 \mathrm{ppm}$ $\mathrm{N}$ from $20 \mathrm{~N}-6.6 \mathrm{P}-17.6 \mathrm{~K}$.

Juvenility and flowering requirements of Coreopsis grandiflora 'Sunray' and C. lanceolata 'Early Sunrise'. Ten plants (replications) of each cultivar were transferred from SD to LD upon reaching the following true leaf stages: 0 (cotyledons only), $2,4,6,8,10,12,14,16,18,20,22,24$; a leaf was defined as possessing a fully expanded lamina. Ten plants of each cultivar remained in SD for the duration of the experiment as controls. Treatments were assigned randomly at the time of sowing. This experiment was conducted June 1990 to Nov. 1990.

Data taken at first flower included: number of days elapsed from seeding and start of LD; number of expanded leaves along the main stem; stem length (from cotyledonary node to uppermost node possessing a visible, reproductive, axillary branch); nonreproductive scape length (from last visible axillary branch to uppermost node possessing a leaf); and leafless scape length (from uppermost nonreproductive node to calyx attachment). First flower was defined as the date when ray florets had expanded perpendicular to the stem attachment. Regression analysis and parabolic minimum point calculations (Rees and Sparks, 1969) were used to analyze the data.

Floral induction, initiation, and LIP effects. One hundred C. lanceolata 'Early Sunrise' plants were grown under SD conditions through the end ofjuvenility (16 leaves per plant, as determined by the above experiment), at which time all were moved to LD conditions, except 10 plants (replications) that remained in SD as controls. Ten plants were transferred back to SD following 6, 8, 10, $12,14,16,18,20,22 \mathrm{LD}$ cycles, with 10 plants remaining in LD for the duration of the experiment. Treatments were assigned randomly at the time of transplanting. This experiment was conducted Jan. 1991 to June 1991.

Data taken at first flower included: number of days elapsed from start of LD; stem length (as described previously); scape length (from last visible axillary branch to calyx attachment); total leaf count; and the number of axillary floral buds (at least $2 \mathrm{~cm}$ in length). At the termination of the experiment, 21 weeks after seeding, reproductive status of each plant was recorded using three categories: vegetative only (no macroscopic evidence of flowers), reproductive but aborted, and reproductive to anthesis. Statistical analysis included chi-square, regression analysis, and analysis of variance (ANOVA) methods.

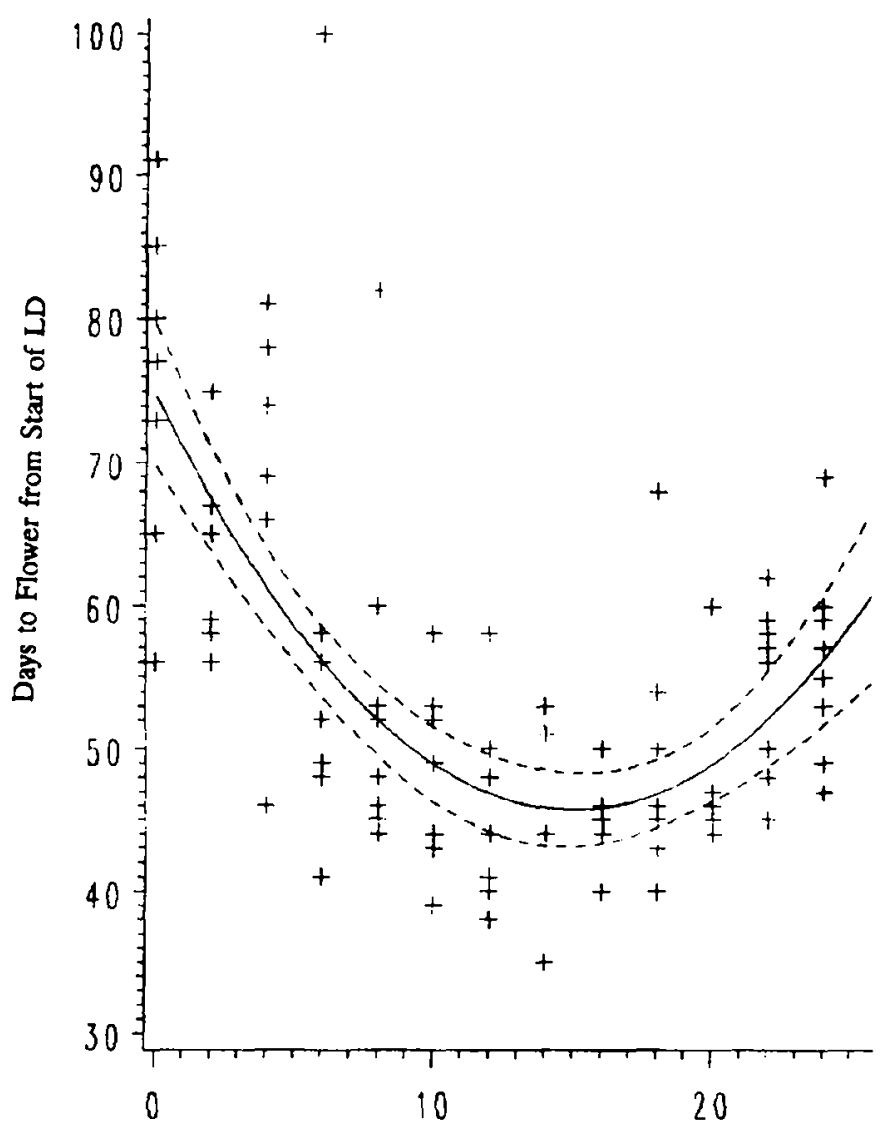

Leaf Count at Transfer to LD

Fig. 1. Effect of leaf count at transfer to long days (LD) on number of LD needed for flowering of Coreopsis lanceolata 'Early Sunrise' $y=74.7-3.87 x+0.129 x^{2}$, $R^{2}=0.44^{\circ *} ;$ parabolic minimum point is 16 leaves, 46 days to flowering; area bound by dashed lines indicates a $95 \%$ confidence interval. 


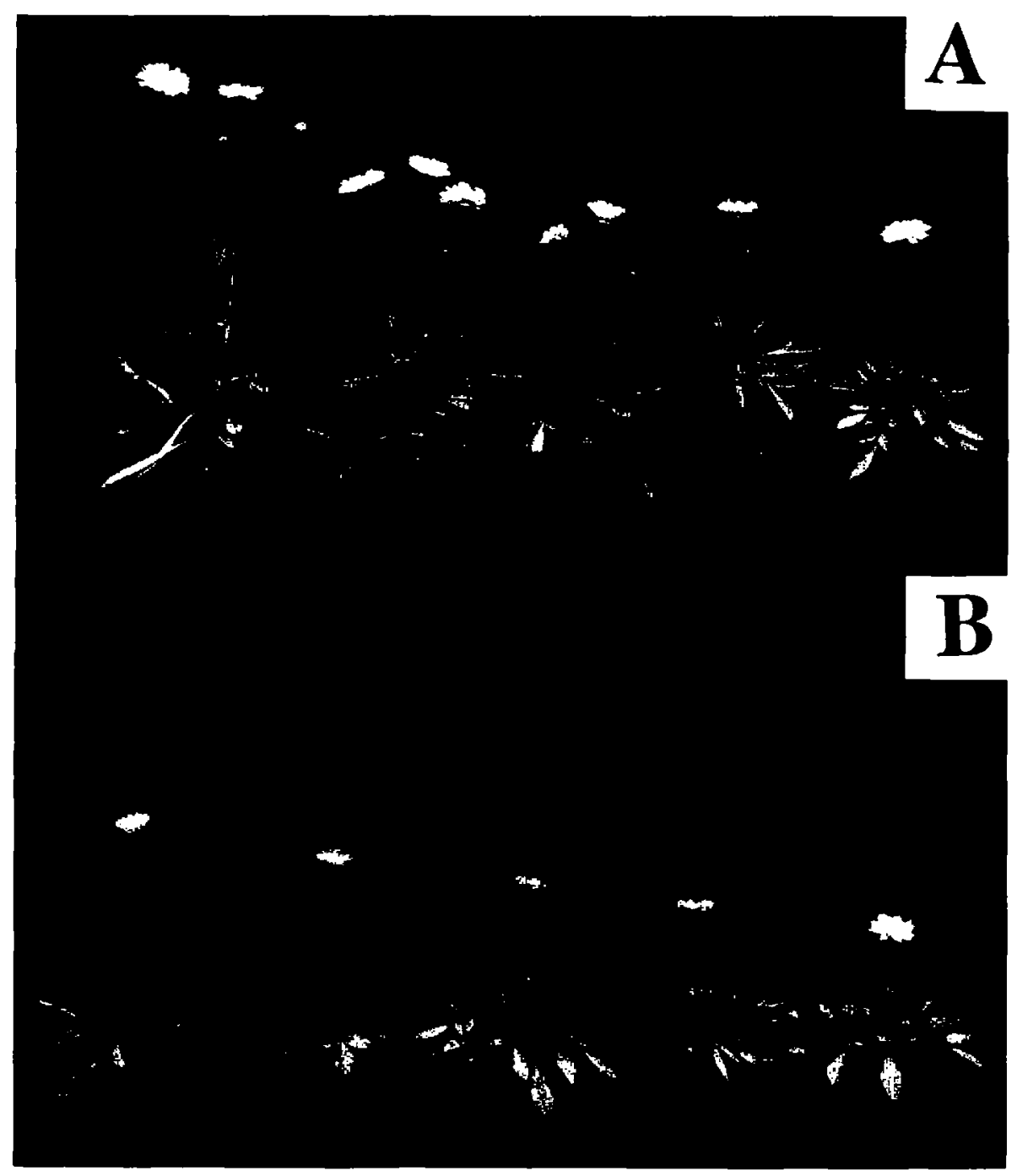

\section{Results}

Juvenility and flowering requirements of Coreopsis grandiflora 'Sunray' and C. lanceolata 'Early Sunrise'. 'Sunray' plants did not flower in any treatment group. 'Early Sunrise' plants remained vegetative in SD, but $70 \%$ to $90 \%$ flowered in LD. Lack of $100 \%$ flowering was random and not attributed to specific leaf count treatments. There was no significant linear or quadratic relationship between plant leaf count at the onset of LD and stem length, nonreproductive scape length, leafless scape length, or total height at first flower.

A quadratic relationship existed between the number of days to flowering after the onset of LD and plant leaf count when first moved to LD (Fig. 1). The parabolic minimum calculation indicated that plants flowered most quickly at 46 days, when transferred to $\mathrm{LD}$ at the 16 leaf stage. In contrast, plants transferred at the cotyledon and 24 leaf stages required 75 and 56 days, respectively, to flower. Similar quadratic relationships were also observed between plant leaf count at the start of LD and: number of days from sowing to flower $\left(R^{2}=0.59 * *\right.$; y $=88.2-1.41 \times+$ $\left.0.125 \mathrm{x}^{2}\right)$, and total leaf count per plant at first flower $\left(R^{2}=0.80 * *\right.$; $\left.\mathrm{y}=24.1-0.281+0.0448 \mathrm{x}^{2}\right)$ (data not shown).
Floral induction, initiution, and LIP effects. Flowering ranged from $80 \%$ to $100 \%$ across treatments, and chi-square analysis indicated that the duration of the LIP treatment had no effect on the percentage of plants flowering in those treatments. Scape length, number of axillary flower buds, and total leaf count at first flower followed no significant linear or quadratic relationship with the number of LD received before transfer back to SD. With SD and LD control plants deleted from the data set, there was a quadratic relationship ( $R^{2}=0.48^{* *}$ ) between the number of LD received and total plant height at first flower (Fig. 2). Plants given six LD before transfer to SD were $10 \mathrm{~cm}$ shorter than plants that received $22 \mathrm{LD}$. The relationship between the number of $L D$ received and stem length at first flower was also quadratic (Fig. 3); plants receiving only six LD averaged $2.3 \mathrm{~cm}$ stems, whereas those receiving $22 \mathrm{LD}$ averaged $13.5 \mathrm{~cm}$ (Fig. 4). A linear relationship between number of LD received and number of days to first flower indicated that plants given $22 \mathrm{LD}$ before the switch back to SD would flower $\approx 92$ days from start of LD, whereas those given only six LD would require 10.5 days to flower after onset of $\mathrm{LD}$ (Fig. 5).

The control groups, excluded from the previous regression analyses, were compared to each other and the other treatments via mean separation tests (Table 1). There were more axillary flower 
buds on LD-control plants than on SD-control plants or on plants that received 6,8 , and $14 \mathrm{LD}$. SD-control plants averaged less than a single axillary flower bud and required 20 additional days to flower than plants in any of the LD treatment groups.

\section{Discussion}

The definitive flowering studies with C. grandiflora were based on the responses of the 'Single Mayfield Giant' to photoperiodic manipulation (Ketellapper and Barbaro, 1966). Neither 54 weeks LD nor 40 weeks LD followed by 14 weeks SD elicited flowering. Only 40 weeks SD alone or the previous LD-SD combination immediately followed by eight additional weeks LD promoted flowering. The species was subsequently classified as a SLD plant, which was confirmed $>20$ years later (Metzger, 1988). This complex photoperiodic classification should not, however, be considered exclusive for the species. The 'Sunray' never flowered in the present research despite a 10 week exposure to SD followed immediately by transfer to LD. 'Early Sunrise' also defied the SLD label. Plants grown solely in LD from germination flowered as well as any plants grown in SD before being transferred to LD. Furthermore, neither 'Sunray' nor 'Early Sunrise' plants flowered after 20 weeks in SD, albeit half the duration described by Ketellapper and Barbara (1966). Therefore, the photoperiodic flowering nature of at least these two Coreopsis cultivars is not linked to SD.

Ketellapper and Barbaro (1966) also discussed a juvenile phase during which Coreopsis plants were insensitive to SD or less

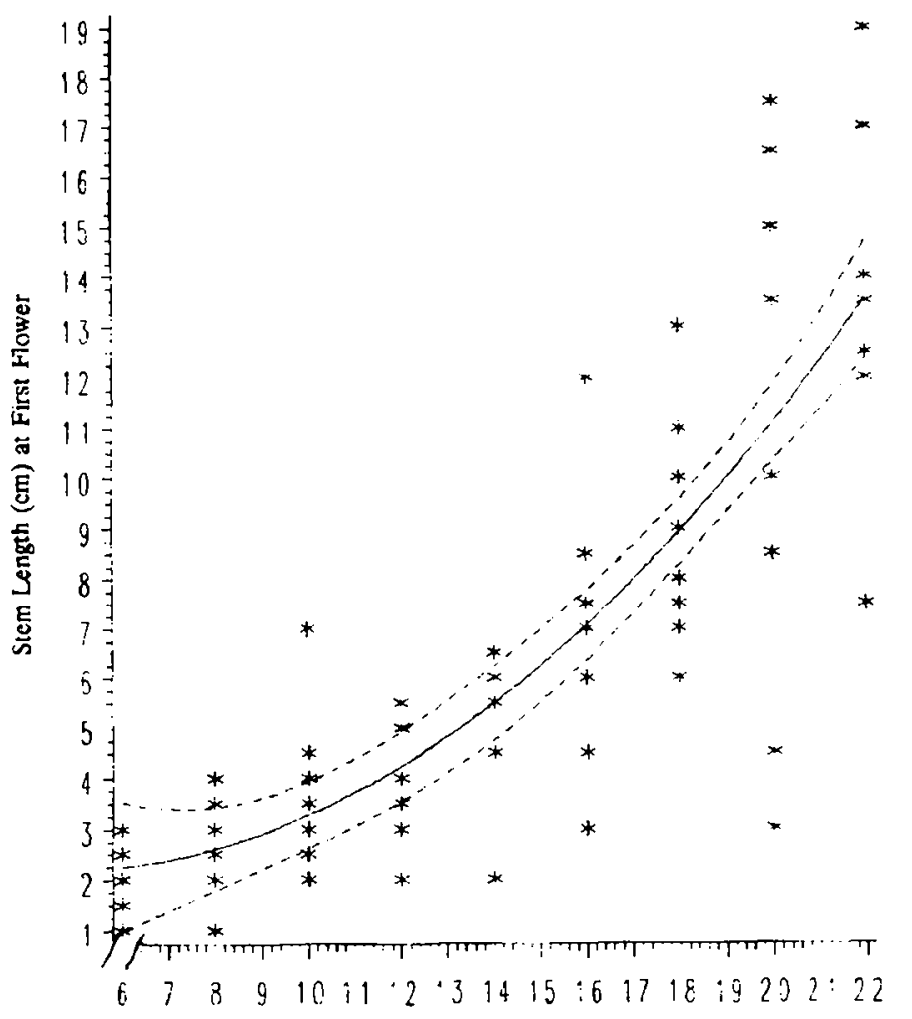

Number of LD Received

Fig. 3 Effect of a limited number of inductive long day (LD) cycles received by Coreopsis lancelata 'Early Sunrisc on stem length at first flower. $y=3.10-$ $0.353 \mathrm{x}+0.037 \mathrm{x}^{2}, R^{2}=0.72^{\circ}$ : area bound by dashed lines indicates a $95 \%$ confidence interval. sensitive than older plants. Such a phenomenon characterized $C$. lanceolata 'Early Sunrise', but with respect to LD, not SD conditions. Our results indicated that this cultivar was most sensitive to LD at a calculated expanded leaf count of 16 . when, theoretically. it would flower 46 days after placement in LD. A more appropriate description ofjuvenility loss may be a leaf count range, rather than a specific leaf stage, based on the upper and lower limits of the $95 \%$ confidence interval. In this case, 'Early Sunrise' plants possessing nine to 21 expanded leaves at the start of LD would flower most rapidly (Fig. I ). This range is similar to juvenility loss ranges in other members of the Asteraceae: 15 to 24 leaves in Rudbeckia and 14 to 20 leaves in Gaillardia pulchella (Bourke, 1990). Yet, it is slightly higher than the six to 14 leaves needed for Eschscholtzia californica to pass through juvenility (Lyons and Booze-Daniels, 1986).

In determining a juvenility relationship between plant age and SD sensitivity, Ketellapper and Barbaro (1966) found that C. grandiflora seedlings grown in LD for 9 weeks or less before their reported SD requirement did not flower upon return to LD. However, after 15 to 20 weeks of initial LD growth, 7 weeks of SD became sufficient to promote flowering in all plants upon their return to $\mathrm{LD}$. By contrast, in the present experiment, plants transferred from SD to $\mathrm{LD}$ at the 20 leaf stage were grown in noninductive conditions for $\approx 9$ weeks, and 90\%: of them flowered. Therefore, in breeding $C$. lanceolata 'Early Sunrise', the juvenility period has been greatly reduced, and the need for any SD exposure appears to have been eliminated. Further, while $C$. grandiflora 'Single Mayfield Giant' first became photoperiodically sensitive 15 to 20 weeks after germination (Ketellapper and Barbaro, 1966), 'Early Sunrise' plants, with fewer leaves than would be expected after 15 to 20 weeks of growth, flowered with a frequency in excess of $70 \%$ upon transfer to LD.

The fact that $C$. grandiflora 'Sunray' did not flower in SD or any SLD conditions in the 20 weeks allowed in the current work may be attributed to the duration of the experiment when compared to the 40 weeks allotted by Ketellapper and Barbaro (1966). However, it is clearthat the floral initiation requirements of 'Sunray' are quite unlike those of 'Single Mayfield Giant', pointing again to cultivar diversity or raising the possibility of taxonomic misclassification. Even though $C$. lanceolata 'Early Sunrise' flowered under continuous SD, this does not necessarily contradict a LD plant classification. The closely related, obligate LD plant Rudbeckia hirta (syn: $R$. bicolor), also eventually flowered under SD when kept at a constant 32C (Murneek, 1940); late, sporadic flowering was reported for $R$. hirta 'Marmalade' when temperatures occasionally reached 25C (Orvos and Lyons, 1989). In the present study, LD treatments began on 1 Feb., and first flowering was completed by mid-June. Despite cooling systems. there were times when the greenhouse reached 28 to 33C. which could account for flowering in SD.

The minimum number of LD cycles required for floral initiation in C. lanceolata 'Early Sunrise' is comparatively few, given that $80 \%$ of the plants flowered after receiving only six LD cycles. In contrast, Greulach ( 1942) reported that 18 LD cycles were needed just to achieve sparse flowering of the related species Coreopsis tinctoria Nutt., and 10 to $17 \mathrm{LD}$ cycles were required for flowering of other selected members of the Asteraceae. We also observed no aberrations in floral morphology in 'Early Sunrise' plants subjected to LIP. This result is contrary to the "vegetative," or abnormal, flowers reported in similar LIP studies involving $R$. hirta (Beckwith. 1991; Greulach, 1942; Murneek 1936, 1940). However, as reported for $R$. hirta (Orvos and Lyons. 1989), 'Early Sunrise' plants that received relatively few LD cycles were slower 


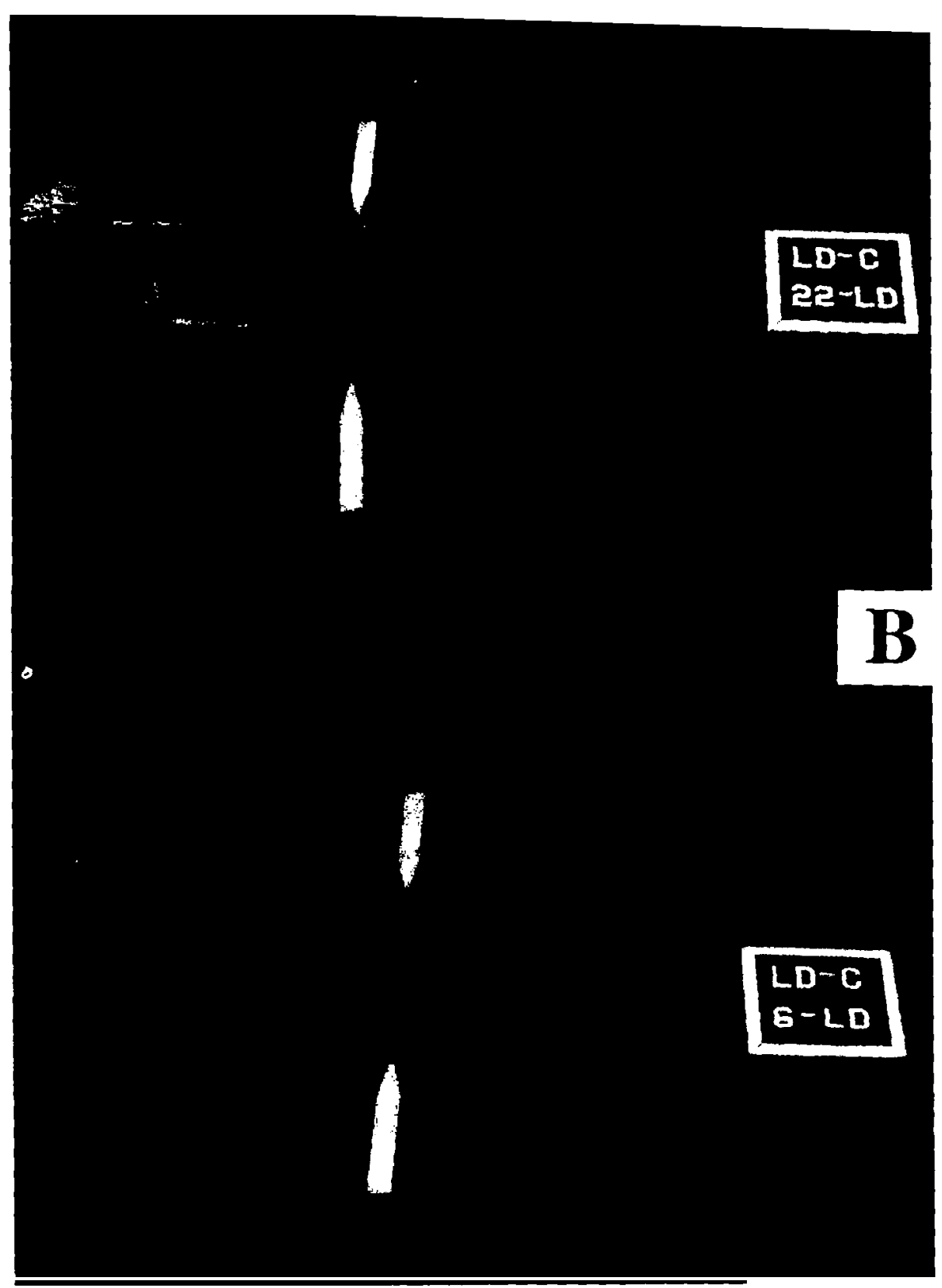

Fig. 4 Effect of a limited number of inductive long day (LD) cycles on Coreopsis lanceslara 'Early Sunrise' stem and scape elongation: A L.D-control plant (LD-C) compared with (A) a plant that received 22 LD 22-LD) before iransfer to shor days (SD), and $(\mathbf{B})$ a plant which received 6 LD (6-LD) before transfer to SD. Plants have been stripped of all leaves except those at the stem-scape junction (indicated by pointers).

to flower and shorter, primarily due to an inhibitory effect of LIP on stem elongation.

Flowering and bolting have been shown to be related, but separable processes in many plants (Bernier et al.. 1981b: Greulach, 1942; Murneek, 1936, 1940: Orvos and Lyons, 1989; Zeevart, 1976). If flowering is solely the result of the initiation and development of a reproductive structure, then bolting itself can be further separated into the independent contributions of the stem - ..e nnemintly different control mechanisms. cycle number) without any visible effect on the floral capitulum, as previously observed in R. hirta (Orvos and Lyons, 1989). Yet, the observed height reduction was primarily attributable to an inhibition of stem elongation related to the termination of inducive LD, leaving scape length relatively unaltered by LIP. Thus, in C. lanceolata 'Early Sunrise', once floral initiation has irreversibly occurred, scape elongation appears to be considerably less affected by prevailing photoperiod, quite unlike stem elongation. While LIP appears to be an alternative to chemical means for 


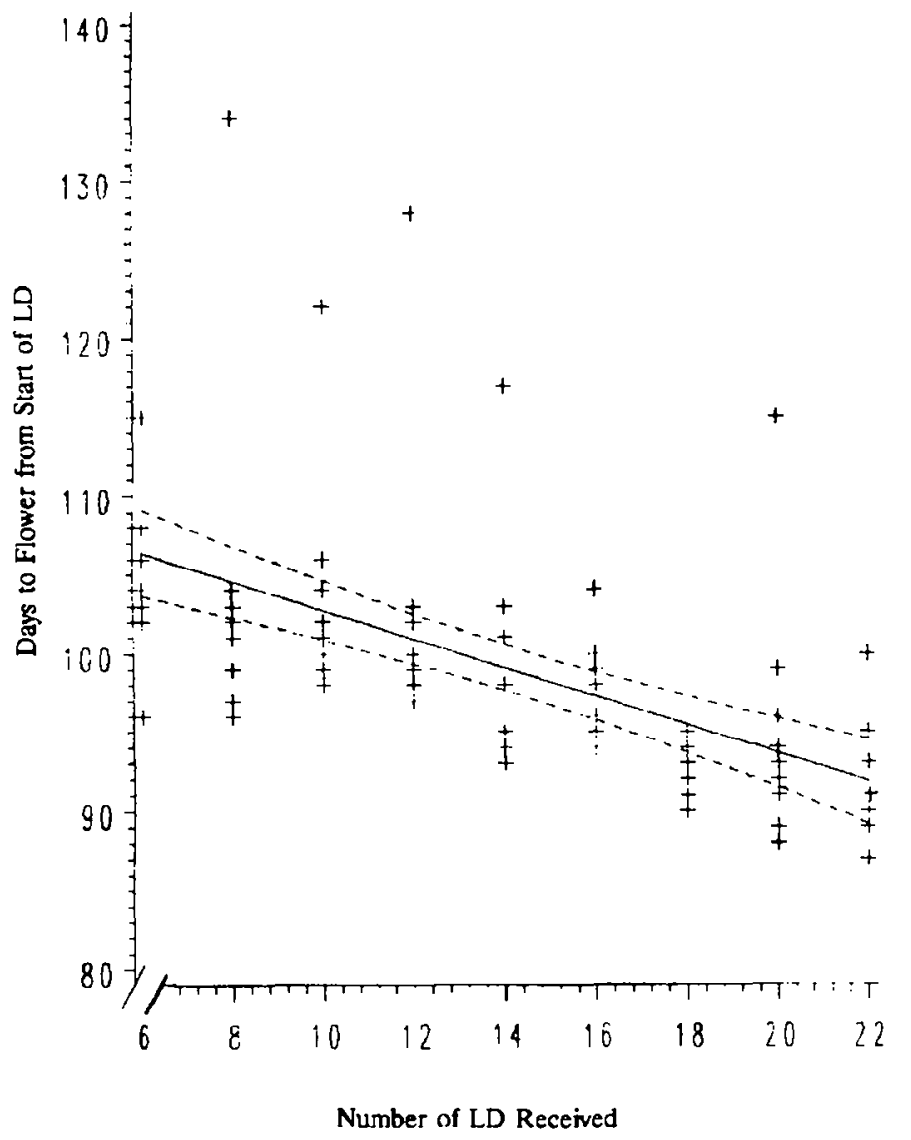

Fig. 5 Effect of a limited number of inductive long day (LD) cycles received by Coreopsis lanceolata 'Early Sunrise' on number of days to flower from start of LD. $y=110.0-0.829 \mathrm{x}, R^{2}=0.34^{\circ}$ : area bound by dashed lines indicates a $95 \%$ confidence interval.

Table 1 . The effect of specified inductive long day (LD) cycles received by Coreopsis lanceolata 'Early Sunrise' on number of days to flower from start of LD and number of axillary flower buds.

\begin{tabular}{lcc}
\hline No. of LD & $\begin{array}{c}\text { No. of days to } \\
\text { flower from } \\
\text { start of LD }\end{array}$ & $\begin{array}{c}\text { No. of } \\
\text { flower buds }\end{array}$ \\
\hline LDC $^{2}$ & $91 \mathrm{c}^{y}$ & $6.1 \mathrm{a}$ \\
22 & $91 \mathrm{c}$ & $5.5 \mathrm{abc}$ \\
20 & $95 \mathrm{c}$ & $5.2 \mathrm{abc}$ \\
18 & $93 \mathrm{c}$ & $5.9 \mathrm{ab}$ \\
16 & $99 \mathrm{bc}$ & $5.7 \mathrm{ab}$ \\
14 & $100 \mathrm{bc}$ & $3.3 \mathrm{bcd}$ \\
12 & $103 \mathrm{~b}$ & $4.7 \mathrm{abcd}$ \\
10 & $103 \mathrm{~b}$ & $3.7 \mathrm{abcd}$ \\
9 & $104 \mathrm{~b}$ & $3.0 \mathrm{~cd}$ \\
6 & $105 \mathrm{~b}$ & $2.5 \mathrm{~d}$ \\
SDC $^{\mathrm{n}}$ & $125 \mathrm{a}$ & $0.1 \mathrm{c}$
\end{tabular}

${ }^{2}$ Continuous long day controls.

y Means separation within columns by Student-Newman-Keuls test, $P=$ 0.05 .

${ }^{x}$ Continuous short day controls.

terminated before anthesis for a photoperiodic plant. However, axillary flower bud count was not sacrificed in Coreopsis lanceolata 'Early Sunrise' when LIP was employed. Limiting the number of LD to 22 inhibited stem length and total height, with no loss of axillary bud potential. In fact, axillary flower bud count and days to first flower from either sowing or the start of LD remained unaffected with as few as 16 LD when compared to LD control plants. Our data also indicate that one can expect the number of days to flower from seeding to be about twice as many as that required from the start of LD. Ambient greenhouse conditions and seasonal changes in light could, of course, affect this relationship.

The flowering behavior of Coreopsis cultivars apparently is not only diverse, but simpler and more easily manipulated than previously reported (Ketellapper and Barbaro, 1966). The use of LIP also merits additional attention as a height control technique, applicable to the potted plant production of $C$. lanceolata 'Early Sunrise' and to other LD-bolting species having ornamental potential.

\section{Literature Cited}

Anon. 1988. Floriculture Crops. 1987 Summary. U.S. Dept. of Agr., Natl. Agr. Stat. Serv., Agr. Stat. Board. Washington D.C.-SpCr 6-1 (XX).

Beckwith. D.D. 1991. Characterization of juvenility and photoperiodic response of Rudbeckia hirta originating from different latitudes. MS Thesis. Dept. of Hort., Virginia Polytechnic Institute and State Univ., Blacksburg.

Bernier, G., J. Kinet, and R.M. Sachs. 1981a. The physiology of flowering: vol. 1. CRC Press. Boca Raton, Fla. p. 106-107.

Bernier, G.. J. Kinet, and R.M. Sachs. 1981 h. The physiology of flowering: vol. 2. CRC Press. Boca Raton. Fla. p 22.

Bourke, K.M. 1990. Juvenility in three composite genera with ornamental potential: Rudbeckia, Gaillardia. and Solidago. MS Thesis. Dept. of Hort., Virginia Polytechnic Institute and State Univ., Blacksburg.

Carter, K.F. 1986. Description and control of flowering in California poppy ( Eschscholtzia californica Cham.). MS Thesis. Dept. of Hort., Virginia Polytechnic Institute and State Univ., Blacksburg.

Cathey, H.M. 1981. Assessment of research needs for floriculture priorities: Proposals. Report from the D.C. Kiplinger Chair in Floriculture. Dept. of Horticulture, Ohio State Univ., Columbus.

Clausen, R.R. and N.H. Ekstrom. 1989. Perennials for American gardens. Random House, New York, p. 153-155.

Cumming, B.C. 1959. Extreme sensitivity of germination and photoperiodic reaction in the genus Chenopodium, Nature (London) 184:1044-1045.

Friend, D.J.C. 1968. Photoperiodic responses of Brassica compestris cv. Ceres. Physiol. Plant. 21:990-1002.

Greulach, V.A. 1942. Photoperiodic after-effects in six composites. Bot. Gaz. 103:698709

Hackett, W.P. 1985. Juvenility, maturation and rejuvenation in woody plants. Hort. Rev. vol. 7. p. 111-1 12 .

Herbert, E. 1977. Preferences key to profits. Flor. Rev. 160 (4148): 27.

Ketellapper, H.J. and A. Barbaro. 1966. The role of photoperiod, vernalization, and gibberellic acid in floral induction, in Coreopsis grandiflora Nutt. Phyton 23:33-41.

Laurie, A. and G.H. Poesch. 1932. Photoperiodism. The value of supplementary illumination and reduction of light on flowering plants in the greenhouse. Ohio Agr. Expt. Sta. Bul. 512:142.

Liberty Hyde Bailey Hortorium, 1976. Hortus third: A concise dictionary of plants cultivated in the United States and Canada. Macmillan, New York.

Lyons. R.E. and J.N. Booze-Daniels. 1986. Characteristics of the photoperiodic response of California poppy. J. Amer. Soc. Hort. Sci. 111:593-596.

Lyons. R.E. and L. Neale. 1983. Effect of photoperiod. gibberellin and ancymidol on flowering and vegetative development of California poppy (Eschscoltzia californica Cham.). HortScience 18573 (Abstract)

Metzger, J.D. 1988. Hormones and reproductive development, p. 431-443. In: P.J. Davies (cd.). Plant hormones and their role in plant growth and development. Kluwer Academic Publ., Dordrecht, The Netherlands.

Murneek, A.E. 1936. A separation of certain types of responses of plants to photoperiod. Proc. Amer. Soc. Hort. Sci. 34:507-509.

Murneek, A.E. 1940. Length of day and temperature effects in Rudbeckia, Bot. Gaz. 102:269-279.

Orvos, A.R. and R.E. Lyons. 1989. Photoperiodic inhihition of stem elongation and flowering in Rudbeckia hirta 'Marmalade'. J. Amer. Soc. Hort. Sci. 114:219-222.

Purvis, O.N. 1934. An analysis of the influence of temperature on the subsequent development of certain winter cereals and its relation to the effect of length of day. Ann. Bot. 48:919-955.

Rees, P.K. and F.W. Sparks. 1969. Calculus with analytic geometry. McGraw-Hill, New York.

Schwabe, W.W. 1976. Applied aspects of juvenility and some theoretical considerations. Acta Hort. 56:45-53.

Warcing, P.F. and V.M. Frydman. 1976. General aspects of phase change, with special reference, to Iledera helix L. Acta Hort. 56:63-69.

Zeevart, J.A.D. 1976. The physiology of flower formation. Ann. Rev. Plant. Phys. 27:321-348. 